\title{
Prediction of favourable responses to long term vasodilator treatment of pulmonary hypertension by short term administration of epoprostenol (prostacyclin) or nifedipine
}

\author{
ADRIAN ROZKOVEC, * JOHN R STRADLING, $\dagger$ GILLIAN SHEPHERD, \\ JOHN MACDERMOT, $\ddagger$ CELIA M OAKLEY, * COLIN T DOLLERY $\ddagger$ \\ From the Departments of Medicine ( ${ }^{\star}$ Clinical Cardiology and $\nmid$ Respiratory Medicine) and $\ddagger$ Clinical \\ Pharmacology, Hammersmith Hospital and Royal Postgraduate Medical School, London
}

SUMMARY Eighteen patients with moderate to severe pulmonary hypertension were studied, nine with intracardiac shunts and nine without. The effects of an incremental infusion of epoprostenol (prostacyclin) (0.5-8 ng/kg per minute) or sublingual nifedipine (20-30 mg) were compared with the response to three months' treatment with oral nifedipine.

Both epoprostenol and sublingual nifedipine caused a fall in pulmonary vascular resistance and pressure and a rise in cardiac output. Patients with intracardiac shunts had higher systemic blood flows than those without shunts. Exercise in the shunt group was accompanied by systemic desaturation and hyperventilation. Analysis of individual results showed that the size of the response was inversely related to the severity of the pulmonary vascular disease. A good long term response to nifedipine seemed to be as readily predicted by the resting control values for haemodynamic variables as by values after short term treatment. A favourable response was likely if the pretreatment mean pulmonary artery pressure was $<50 \mathrm{~mm} \mathrm{Hg}$, the ratio of total pulmonary to systemic resistance was $<0 \cdot 7$, or the ratio of mean pulmonary artery pressure to systemic artery pressure was $<0 \cdot 6$.

Short term vasodilator protocols may do harm. If such studies are carried out, an adequate dose range must be tried before the long term efficacy of an individual drug can be forecast.

Vasodilator treatment can produce a favourable haemodynamic response and improve exercise performance in some patients with pulmonary hypertension. In more advanced disease a vasodilator may be ineffective because pulmonary vascular obstruction has become fixed and there is no vascular reserve. In such patients these drugs may do harm. It is not known whether the response to short term treatment, if favourable, is predictive of long term benefit. In the few studies designed to answer this question patient numbers have been too small, there has been subselection of patients after the short term vasodilator trial, or failure to standardise the long term treatment. ${ }^{1-3}$ When different vasodilators are evaluated the agents under test should be given to the same

Requests for reprints to Dr Adrian Rozkovec, Cardiac Department, Bristol Royal Infirmary, Marlborough Street, Bristol BS2 8HW.

Accepted for publication 9 November 1987 patients. Comparative studies suggest that some agents are better than others, ${ }^{4-6}$ but none of these used a series of doses to cover the therapeutic range. There is therefore a need for a trial of the effects of vasodilator agents over a wide dose range to compare the short term and subsequent long term responses.

\section{Patients and methods}

\section{METHODS}

Table 1 shows the clinical details of the 18 patients we studied. All had normal resting left ventricular function (table 2) and were stable at the time of the short term study, although three had clinical evidence of right heart failure (patients 7, 8, and 9). The diagnosis of primary pulmonary hypertension required the exclusion of embolic and restrictive lung disease that could have contributed to the hypertension. ${ }^{78}$ 


\section{SHORT TERM STUDY}

We tested fourteen patients (table 1). For two weeks before the study they were kept off drugs that affected platelet function or blood coagulation. They were fasted overnight and were given $10 \mathrm{mg}$ diazepam as premedication. The variables given in the tables and figures were measured by standard cardiac catheterisation procedures. There was an interval of at least one hour between angiography and the first set of measurements. Pressures were measured by Statham P23 Gb transducers connected to an E for M VR12 recorder and averaged over one or more respiratory cycles. ${ }^{9}$ Dextrose solution $(5 \%)$ containing three units of heparin per $\mathrm{ml}$ was used to flush the lines. No more than one litre of fluid was given during the procedure. Caffeine containing drinks were not permitted. ${ }^{10}$ Total blood loss for sampling did not exceed $200 \mathrm{ml}$.

Table 1 Data on patients in the study

\begin{tabular}{|c|c|c|c|c|c|c|c|c|c|c|}
\hline \multirow{2}{*}{$\begin{array}{l}\text { Patient } \\
\text { No }\end{array}$} & \multirow[b]{2}{*}{ Sex } & \multirow{2}{*}{$\begin{array}{l}\text { Age } \\
(y r)\end{array}$} & \multicolumn{2}{|c|}{ Disease classification } & \multirow{2}{*}{$\begin{array}{l}\text { Exra- } \\
\text { pulmonary } \\
\text { shunt }\end{array}$} & \multirow{2}{*}{$\begin{array}{l}V / Q \\
\text { scan }\end{array}$} & \multirow{2}{*}{$\begin{array}{l}\text { Pulmonary } \\
\text { angiogram }\end{array}$} & \multicolumn{2}{|l|}{ Short term } & \multirow{2}{*}{$\begin{array}{l}\text { Long term } \\
\text { exercise }\end{array}$} \\
\hline & & & Primary & Secondary & & & & Epoprostenol & Nifedipine & \\
\hline 1 & $\mathbf{F}$ & 26 & $\mathbf{P}$ & & & C & C & + & + & + \\
\hline 2 & $\mathbf{F}$ & 55 & $\mathbf{P}$ & & & C & C & + & + & + \\
\hline 3 & $\mathbf{F}$ & 45 & $\mathbf{P}$ & & & C & C & + & + & + \\
\hline 4 & $\mathbf{F}$ & 56 & $\mathbf{P}$ & $\mathrm{CRST}^{\star}$ & & C & C & + & + & + \\
\hline 5 & $\mathbf{F}$ & 41 & $\mathbf{P}$ & SLE† & & C & C & + & + & \\
\hline 6 & $\mathbf{F}$ & 30 & $\mathbf{P}$ & & & C & C & + & + & \\
\hline 7 & $\mathbf{F}$ & 24 & PE & & & C & C & + & + & \\
\hline 8 & $\mathbf{M}$ & 43 & $\overline{P E}$ & & & C & C & + & + & \\
\hline 9 & $\mathbf{M}$ & 59 & $\overline{\mathbf{P E}}$ & & & C & C & + & + & \\
\hline 10 & $F$ & 31 & P PFO & & + & C & C & + & & + \\
\hline 11 & $\mathbf{M}$ & 22 & P PFO & PE $\ddagger$ & + & NC & NC & + & + & + \\
\hline 12 & $F$ & 34 & E ASD & & + & C & C & & + & \\
\hline 13 & $\mathbf{F}$ & 50 & E ASD & & + & C & - & + & + & \\
\hline 14 & $\mathbf{F}$ & 24 & E PDA & & + & - & C & + & + & + \\
\hline 15 & $\mathbf{F}$ & 21 & E VSD & & + & - & C & & & + \\
\hline 16 & $\mathbf{M}$ & 20 & $\begin{array}{l}\text { E PDA + } \\
\text { VSD }\end{array}$ & & + & - & C & & & + \\
\hline 17 & $\mathbf{M}$ & 35 & E PDA & & + & - & C & & & + \\
\hline 18 & $\mathbf{F}$ & 23 & E VSD & & + & - & C & & & + \\
\hline
\end{tabular}

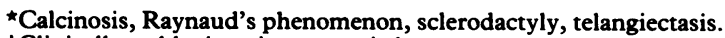

†Clinically stable, inactive systemic lupus.

$\ddagger$ Previous episode of septic pulmonary emboli.

ASD, atrial septal defect; C, result consistent with diagnosis; E, Eisenmenger's syndrome; NC, result not entirely consistent with diagnosis (see text); P, primary pulmonary hypertension; PE, chronic pulmonary thromboembolism; PFO, patent foramen ovale; PDA, patent ductus arteriosus; VSD, ventricular septal defect; $\grave{V} / Q$, ventilation perfusion lung scan.

Table 2 Baseline values for short term study

\begin{tabular}{|c|c|c|c|c|c|c|c|c|c|c|c|}
\hline $\begin{array}{l}\text { Patient } \\
\text { No }\end{array}$ & $\begin{array}{l}B S A \\
\left(m^{2}\right)\end{array}$ & $\begin{array}{l}\mathrm{VO}_{2} \\
(\%)\end{array}$ & $\begin{array}{l}\mathrm{SaO}_{2} \\
(\%)\end{array}$ & $\begin{array}{l}\mathrm{Hb} \\
(\mathrm{g} / 100 \mathrm{ml})\end{array}$ & $\begin{array}{l}\overline{P A} \\
(\mathbf{m m} H g)\end{array}$ & $\begin{array}{l}\overline{S A} \\
(m m H g)\end{array}$ & $\begin{array}{l}C I \\
\left(l / \min \text { per } m^{2}\right)\end{array}$ & $\begin{array}{l}T P V R I \\
\left(U . m^{2}\right)\end{array}$ & $\begin{array}{l}S V R I \\
\left(U \cdot m^{2}\right)\end{array}$ & $\begin{array}{l}R V E D P \\
(m m H g)\end{array}$ & $\begin{array}{l}L V E D P \text { or } \\
P C W \\
(\mathrm{~mm} H g)\end{array}$ \\
\hline $\begin{array}{r}1 \\
2 \\
3 \\
4 \\
5 \\
6 \\
7 \\
8 \\
9 \\
10 \\
11 \\
12 \\
13 \\
14\end{array}$ & $\begin{array}{l}1.81 \\
1.45 \\
1.70 \\
1.35 \\
1.61 \\
1.64 \\
1.85 \\
1.74 \\
1.92 \\
1.79 \\
1.79 \\
1.50 \\
1.44 \\
1.57\end{array}$ & $\begin{array}{r}99 \cdot 0 \\
80 \cdot 1 \\
160 \cdot 0 \\
72 \cdot 6 \\
60 \cdot 0 \\
87 \cdot 4 \\
110 \cdot 0 \\
77 \cdot 3 \\
92 \cdot 5 \\
102.9 \\
103.5 \\
98.5 \\
98.7\end{array}$ & $\begin{array}{l}97 \cdot 0 \\
94 \cdot 0 \\
94 \cdot 1 \\
95 \cdot 1 \\
93 \cdot 4 \\
95 \cdot 3 \\
94 \cdot 4 \\
88 \cdot 5 \\
93 \cdot 0 \\
82 \cdot 5 \\
90 \cdot 9 \\
74 \cdot 0 \\
87 \cdot 0 \\
82.5\end{array}$ & $\begin{array}{l}14 \cdot 1 \\
13 \cdot 8 \\
14 \cdot 8 \\
10 \cdot 0 \\
13 \cdot 0 \\
13 \cdot 5 \\
14 \cdot 8 \\
12 \cdot 4 \\
15 \cdot 4 \\
16 \cdot 0 \\
17 \cdot 1 \\
17 \cdot 3 \\
17 \cdot 3 \\
22 \cdot 0\end{array}$ & $\begin{array}{l}51 \\
52 \\
47 \\
33 \cdot 5 \\
70 \\
62 \\
62 \cdot 5 \\
67 \\
52 \cdot 5 \\
103 \\
84 \cdot 5 \\
(150 / 10) \dagger \\
69 \\
87 \cdot 5\end{array}$ & $\begin{array}{c}107 \\
90 \\
107 \\
66 \\
100 \\
78 \cdot 5 \\
91 \\
78 \cdot 5 \\
86 \cdot 5 \\
78 \\
88 \cdot 5 \\
85 \\
84 \cdot 5 \\
87 \cdot 5\end{array}$ & $\begin{array}{l}2.67 \\
1.05 \\
3.21 \\
1.26 \\
1.22 \\
1.73 \\
1.27 \\
0.93 \\
1.25 \\
2.96 \\
1.87 \\
1.35 \\
3.78\end{array}$ & $\begin{array}{l}19 \cdot 1 \\
49 \cdot 6 \\
14 \cdot 6 \\
27 \cdot 0 \\
57 \cdot 4 \\
41 \cdot 8 \\
49 \cdot 2 \\
72 \cdot 0 \\
42 \cdot 0 \\
64 \cdot 1 \\
50 \cdot 0 \\
\frac{66}{-}\end{array}$ & $\begin{array}{l}37 \cdot 4 \\
79 \cdot 2 \\
30 \cdot 8 \\
49 \cdot 2 \\
75 \cdot 2 \\
41 \cdot 8 \\
59 \cdot 0 \\
67 \cdot 1 \\
51 \cdot 6 \\
65 \cdot 0 \\
33 \cdot 7 \\
\frac{45 \cdot 4}{21 \cdot 3}\end{array}$ & $\begin{array}{l}8 \\
12 \\
12 \\
5 \\
11 \\
7 \\
18 \cdot 5 \\
16 \\
25 \\
9 \\
15 \\
10 \\
11 \\
10\end{array}$ & $\begin{array}{r}9 \\
12 \\
6 \\
6 \\
-\star \\
5 \\
12 \\
4 \\
8 \\
5 \\
9 \\
6 \\
8 \\
7\end{array}$ \\
\hline
\end{tabular}

^No evidence of left ventricular failure on $x$ ray or echocardiogram.

†Right ventricular pressure $(\mathrm{mm} \mathrm{Hg})$.

BSA, body surface area; $\mathrm{CI}$, cardiac index; $\mathrm{Hb}$, haemoglobin; LVEDP/PCW, left ventricular end diastolic pressure or mean pulmonary capillary wedge pressure; $\overline{\mathrm{PA}}$, mean pulmonary artery pressure; RVEDP, right ventricular end diastolic pressure; $\mathrm{SaO}_{2}$, arterial oxygen saturation; $\widehat{S A}$, mean systemic artery pressure; SVRI, systemic vascular resistance index; TPVRI, total pulmonary vascular resistance index; $\mathrm{VO}_{2}$, oxygen consumption, $\%$ predicted. 
Expired gas was collected with a Tissot spirometer or Douglas bag during the final three minutes of each treatment and control period. The volumes were corrected to standard temperature and pressure (dry) and the oxygen content was measured with a Centronic $200 \mathrm{MGA}$ mass spectrometer. Arterial and mixed venous blood samples were drawn over the same period as gas collection, and oxygen saturation was measured by a CO-Oximeter 282. Control measurements were made before each of the three drug phases: ( $a$ ) an epoprostenol infusion starting at $0.5 \mathrm{ng} / \mathrm{kg}$ per minute with the rate doubled every 15 minutes to a maximum of $8 \mathrm{ng} / \mathrm{kg}$ per minute; $(b)$ a four hour epoprostenol infusion at a rate determined by the initial drug response, and (c) $10 \mathrm{mg}$ sublingual nifedipine in three doses 20 minutes apart. The treatment order could not be randomised because of the long duration of action of nifedipine. There was a one hour interval between the successive periods of drug administration. Epoprostenol was prepared freshly in glycine buffer ( $\mathrm{pH} \mathrm{10.4)} \mathrm{containing}$ physiological saline solution to give a final $\mathrm{pH}$ of 9.5$10 \cdot 0$. The infusion was controlled by a Braun pump and given via the side arm of the catheter sheath into the right atrium. Nifedipine was given sublingually from a punctured $10 \mathrm{mg}$ capsule shielded from the light.

\section{LONG TERM STUDY}

The maximum tolerated dose of oral nifedipine was given for three months. Treatment started in hospital and no other medication was given. At the end of three months, patients were exercised while on nifedipine and again one week after it had been stopped. The same protocol was followed on each visit. Patients were exercised on an ElemaSchonander bicycle ergometer with an increase in workload every minute. ${ }^{11}$ The increase was adjusted for each patient so that at least three stages could be completed. The end points were inability to continue through fatigue or dyspnoea, clinically significant arrhythmias, or symptomatic hypotension.

Expired gases were collected and the volume measured by a Parkinson-Cowan dry gas meter, and the concentration of oxygen and carbon dioxide determined by the mass spectrometer. Arterial saturation was monitored with a Hewlett Packard 47201A ear oximeter. ${ }^{12}$ Blood pressure was recorded by an arm cuff at the end of each one minute stage. Two exercise tests were performed one hour apart: in the afternoon (after no more than liquid refreshment in the previous four hours) and between three and six hours after the last dose of nifedipine. Patients rested for 15 minutes on the bicycle before each exercise test, and breathed through the mouthpiece for the last five minutes of the rest period. Measurements were made during the last 15 seconds of each minute of exercise. Gas volumes were corrected to standard temperature and pressure (dry).

Patient participation in the whole study was incomplete (table 1). Because of the risk and the likelihood of a negative response it was difficult to justify repeat cardiac catheterisation or short term vasodilator studies in patients in whom Eisenmenger syndrome had already been diagnosed. Patient 10 did not wish to continue to the nifedipine phase of the short term study. Those excluded from the long term trial had right heart failure and were severely disabled, had effort syncope, or were unable to attend.

STATISTICAL ANALYSIS

For the short term study we used two way analysis of variance with adjustment for missing values. Linear regression and Spearman's rank correlation was used for the subsequent exploration of individual data. For the long term study we used paired and nonpaired Student's $t$ tests, two tailed, for comparisons. Differences where $p<0.05$ were regarded as statistically significant.

\section{Results}

SHORT TERM STUDY

Epoprostenol

We studied 14 patients in the short term study (table 1) but we restricted the statistical analysis to the nine patients who did not have intracardiac shunts. Patients 6 and 13 had an appreciable fall in systemic pressure on the highest dose of epoprostenol and the infusion had to be stopped before completion of the last increment.

During the epoprostenol infusion there were progressive dose related decreases in average pulmonary and systemic arterial pressure and resistance and in the arteriovenous difference for oxygen. Cardiac output, heart rate, and oxygen consumption increased (fig 1, table 3). These changes were all statistically significant by analysis of variance $(p<$ 0.001 ). Arterial oxygen saturation did not alter (mean of 93.9 to $93.1^{\circ}$ ); this result was also found in the patients with shunts.

The responses varied. For each of the variables that were altered by the infusion, a significant part of the observed change was caused by interindividual differences (analysis of variance). Individual responses to epoprostenol were therefore analysed in the eight patients without shunts who received all the doses of epoprostenol up to and including $8 \mathrm{ng} / \mathrm{kg}$ per minute. The baseline haemodynamic variables of the patients showed a range of severity. In general, those with the highest total pulmonary vascular resistance index also had the highest systemic vascular resis- 
Vasodilators in pulmonary hypertension

tance index and the lowest cardiac index and stroke volume index. A low cardiac index was associated with a low systemic blood pressure and resting oxygen consumption (fig $2 a, b, e$ ).

Figure 2 compares the pretreatment values with
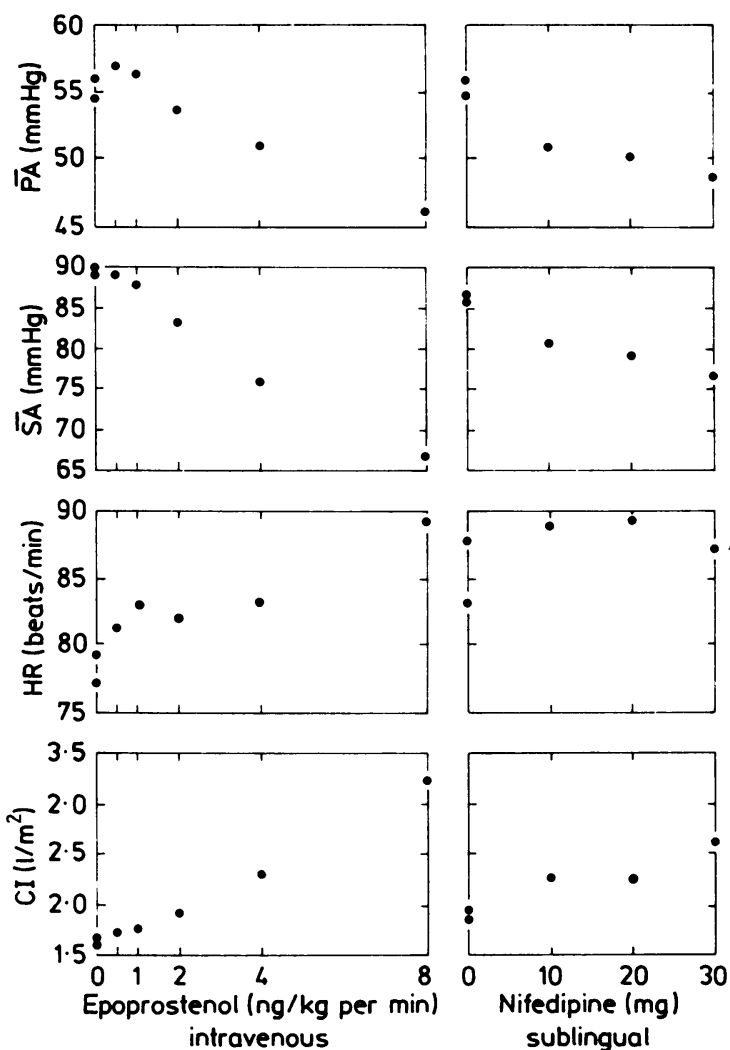

values on the highest dose of epoprostenol; three patients with shunts are included for comparison. The plot of the initial total pulmonary vascular resistance index against the final index shows a significant linear relation $(y=1.16+0.46 x)$ and a
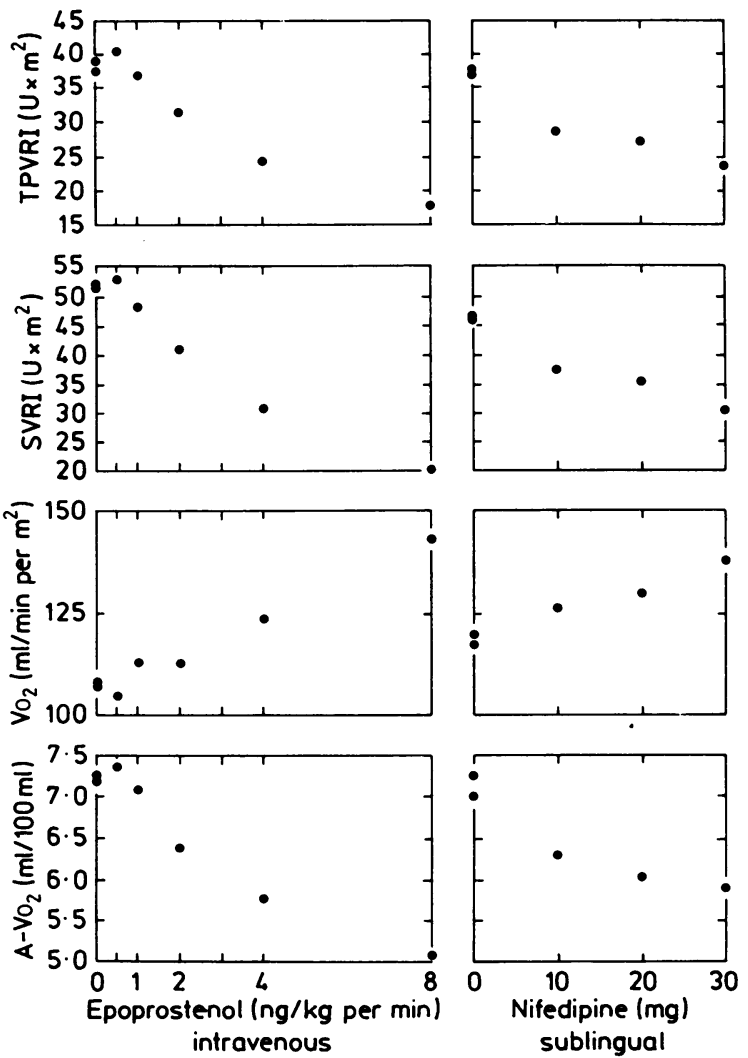

Fig 1 Group responses to epoprostenol or nifedipine in the short term study of pulmonary hypertension. PA, mean pulmonary pressure; $S A$, mean systemic pressure; HR, heart rate; $C I$, cardiac index; TPVRI, total pulmonary vascular resistance index; SVRI, systemic vascular resistance index; $V \mathrm{O}_{2}$, oxygen consumption; $A-V \mathrm{O}_{2}$, arteriovenous oxygen content difference.

Table 3 Drug effects (mean values) in short term study for the nine patients with no intracardiac shunts

\begin{tabular}{|c|c|c|c|c|c|c|c|c|c|c|c|c|}
\hline & \multicolumn{2}{|l|}{ Control } & \multicolumn{5}{|c|}{ Epoprostenol infusion ( $\mathrm{ng} / \mathrm{kg}$ per min) } & \multicolumn{2}{|l|}{ Control } & \multicolumn{3}{|c|}{ Sublingual nifedipine (mg) } \\
\hline & 1 & 2 & 0.5 & 1 & 2 & 4 & 8 & 1 & 2 & 10 & 10 & 10 \\
\hline $\begin{array}{l}\overline{\overline{P A}} \\
\overline{\mathrm{SA}} \\
\overline{\mathrm{PA}} / \overline{\mathrm{SA}} \\
\mathrm{HR} \\
\text { CI } \\
\text { TPVRI } \\
\text { SVRI } \\
\text { TPVRI/SVRI } \\
\mathrm{VO}_{2} \\
\mathrm{~A}-\mathrm{VO}_{2}\end{array}$ & $\begin{array}{c}54 \cdot 6 \\
90 \cdot 3 \\
0 \cdot 61 \\
79 \cdot 4 \\
1 \cdot 67 \\
37 \cdot 7 \\
51 \cdot 5 \\
0 \cdot 74 \\
106 \cdot 9 \\
7 \cdot 16\end{array}$ & $\begin{array}{c}56 \cdot 1 \\
89 \cdot 0 \\
0 \cdot 63 \\
77 \cdot 3 \\
1.59 \\
39 \cdot 2 \\
51 \cdot 8 \\
0 \cdot 76 \\
107 \cdot 9 \\
7 \cdot 26\end{array}$ & $\begin{array}{c}57 \cdot 0 \\
89 \cdot 3 \\
0 \cdot 64 \\
81 \cdot 4 \\
1 \cdot 73 \\
40 \cdot 7 \\
52 \cdot 4 \\
0.78 \\
104 \cdot 3 \\
7 \cdot 35\end{array}$ & $\begin{array}{c}56 \cdot 4 \\
88 \cdot 0 \\
0 \cdot 64 \\
83 \cdot 3 \\
1 \cdot 77 \\
37 \cdot 1 \\
48 \cdot 0 \\
0 \cdot 77 \\
112 \cdot 3 \\
7 \cdot 07\end{array}$ & $\begin{array}{c}53 \cdot 8 \\
83 \cdot 4 \\
0 \cdot 64 \\
82 \cdot 2 \\
1.91 \\
31 \cdot 4 \\
40 \cdot 9 \\
0.77 \\
112.3 \\
6.36\end{array}$ & $\begin{array}{c}51 \cdot 1 \\
76 \cdot 0 \\
0 \cdot 67 \\
83 \cdot 3 \\
2 \cdot 30 \\
24 \cdot 3 \\
30 \cdot 6 \\
0 \cdot 79 \\
123 \cdot 3 \\
5 \cdot 74\end{array}$ & $\begin{array}{c}46 \cdot 2 \\
66 \cdot 7 \\
0 \cdot 69 \\
89 \cdot 2 \\
3 \cdot 22 \\
17 \cdot 7 \\
19 \cdot 9 \\
0 \cdot 89 \\
142 \cdot 8 \\
5 \cdot 05\end{array}$ & $\begin{array}{c}54 \cdot 8 \\
85 \cdot 7 \\
0 \cdot 64 \\
83 \cdot 1 \\
1 \cdot 94 \\
36 \cdot 9 \\
45 \cdot 8 \\
0 \cdot 81 \\
119 \cdot 8 \\
7 \cdot 25\end{array}$ & $\begin{array}{c}56 \cdot 0 \\
86 \cdot 8 \\
0 \cdot 65 \\
87 \cdot 9 \\
1 \cdot 85 \\
37 \cdot 7 \\
46 \cdot 1 \\
0 \cdot 82 \\
117 \cdot 0 \\
6 \cdot 98\end{array}$ & $\begin{array}{c}50 \cdot 2 \\
80 \cdot 9 \\
0 \cdot 63 \\
88 \cdot 8 \\
2 \cdot 26 \\
28 \cdot 6 \\
37 \cdot 2 \\
0 \cdot 77 \\
126 \cdot 2 \\
6 \cdot 26\end{array}$ & $\begin{array}{c}50 \cdot 2 \\
79 \cdot 1 \\
0 \cdot 63 \\
89 \cdot 2 \\
2 \cdot 18 \\
27 \cdot 4 \\
35 \cdot 2 \\
0 \cdot 78 \\
129 \cdot 6 \\
6 \cdot 02\end{array}$ & $\begin{array}{c}48 \cdot 7 \\
76 \cdot 8 \\
0 \cdot 63 \\
87 \cdot 1 \\
2 \cdot 58 \\
23 \cdot 5 \\
30 \cdot 0 \\
0 \cdot 78 \\
137 \cdot 4 \\
5 \cdot 87\end{array}$ \\
\hline
\end{tabular}

$\mathrm{Vo}_{2}, \mathrm{ml} / \mathrm{min}$ per $\mathrm{m}^{2} ; \mathrm{A}-\mathrm{VO}_{2}$, arteriovenous difference in oxygen content $(\mathrm{ml} / 100 \mathrm{ml})$. See table 2 for other abbreviations. 

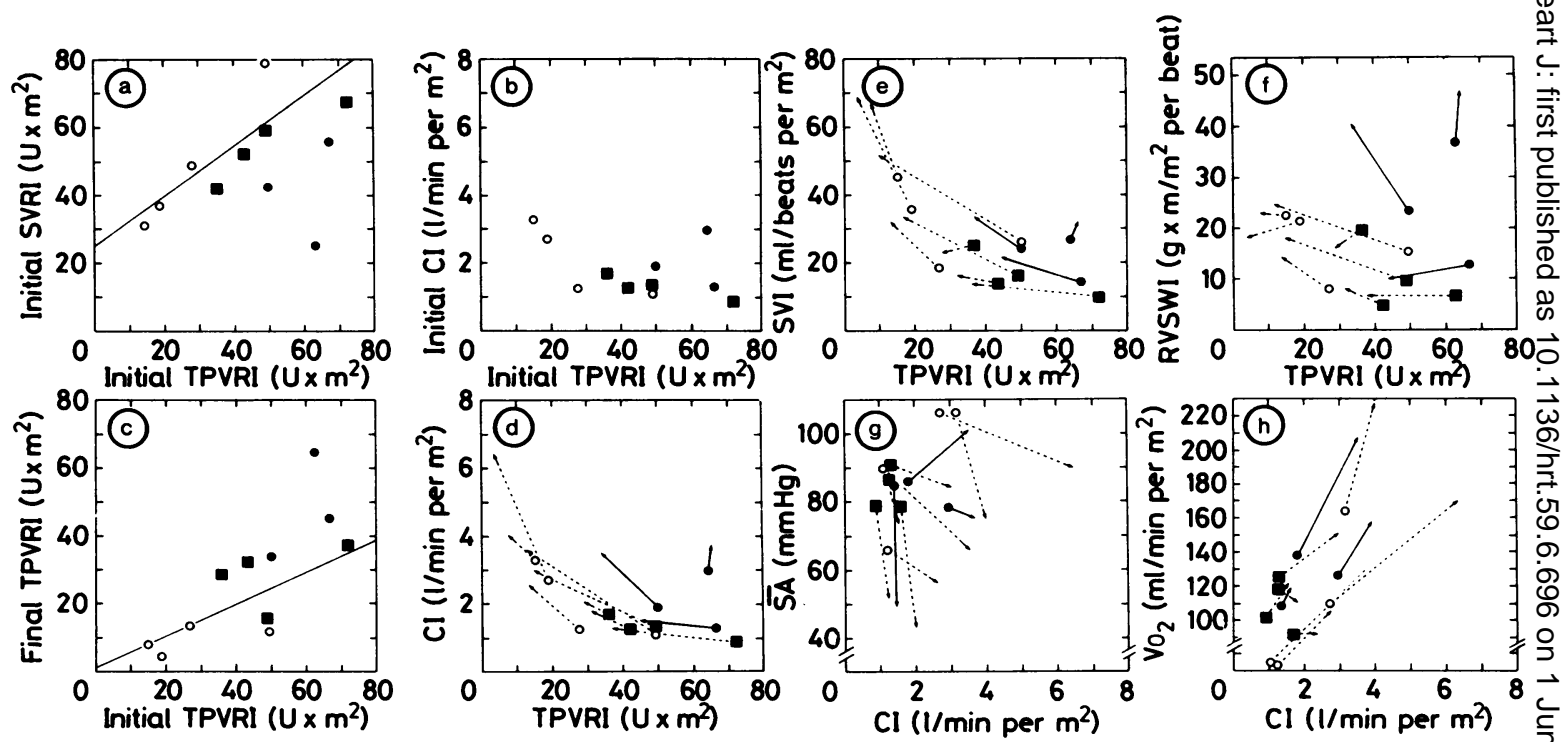

Fig 2 Individual responses to epoprostenol ( $8 \mathrm{ng} / \mathrm{kg}$ per min) in the short term study. $\bigcirc$, responders;

$\square$, non-responders; $O$, patients with shunts. SVI, stroke volume index; RVSWI, right ventricular stroke work index. See legend to fig 1 for other abbreviations.

Correlations:
Pretreatment

(a) $\mathrm{r}=0.82, \mathrm{p}<0.05$

(b) $\mathrm{r}=-0.88, \mathrm{p}<0.01$

(c) $\mathrm{r}=0.71, \mathrm{p}<0.05$

(d) $\mathrm{r}=-0.88, \mathrm{p}<0.01$

(e) $\mathrm{r}=-0.79, \mathrm{p}<0.05$

(f) $\mathrm{r}=-0.65, \mathrm{NS}$

(g) $\mathrm{r}=0.75, \mathrm{p}<0.05$

(h) $\mathrm{r}=0.74, \mathrm{p}<0.05$
Epoprostenol

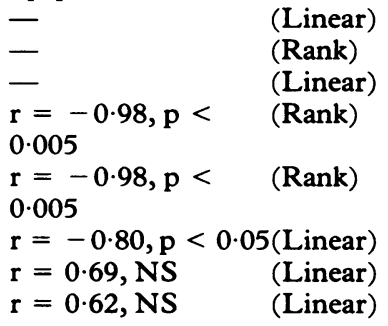

slope less than that of the line of identity (fig 2c). The proportional reduction in pulmonary vascular resistance was generally greater in those with a lower initial resistance value.

The reduction in pulmonary and systemic resistance was accompanied by other changes in haemodynamic function that were usually proportional to the height of the initial pulmonary vascular resistance. Cardiac index and stroke volume index rose, especially in those patients with the lower initial values of total pulmonary vascular resistance index (fig $2 \mathrm{~d}$ and $\mathrm{e}$ ); the rise in oxygen consumption was also greater in these patients (fig $2 \mathrm{~h}$ ). Higher initial cardiac indices were associated with higher systemic pressure and oxygen consumption. The same was true at the end of the epoprostenol infusion (fig $2 \mathrm{~g}$ and $h$ ). Right ventricular stroke work did not alter with epoprostenol (fig 2f).

Another method of displaying the individual changes in pulmonary vascular resistance is to plot pulmonary blood flow against pulmonary artery pressure under control conditions and at the highest dose of epoprostenol (fig 3). In all except one patient the slopes of the lines between the baseline and post-

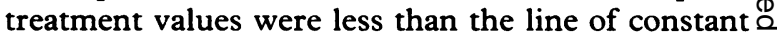
pulmonary vascular resistance. Thus all but one of $\overrightarrow{0}$ the patients showed a reduction in pulmonary vas- 3 cular resistance but, unfortunately, most showed no change in the ratio of pulmonary to systemic artery? pressure throughout the range of epoprostenol doses examined (fig 4). In patient 1 the ratio fell (a $\cong$ favourable response) and in two (patients 5 and 6 ) there was a considerable rise in the ratio.

Five patients had a prolonged epoprostenol infusion. The dose ranged from 2 to $8 \mathrm{ng} / \mathrm{kg}$ per minute and the duration ranged from 40 minutes to o three and a half hours. All developed symptoms, and in three this led to the drug being stopped. When the effect of the dose administered during the prolonged $\frac{N}{N}$ infusion was compared with the effect of the same? dose during the initial part of the study, we found no $N$ significant differences in systemic blood flow $(6.0 \mathrm{~N}$ (3.4) and $5.1(1.4) 1 / \mathrm{min}$ ), mean pulmonary artery pressure $(66.8(38.6)$ and $65.6(39.7) \mathrm{mm} \mathrm{Hg})$, or 6 mean systemic pressure $(78.8(7 \cdot 2)$ and $82.6(15.3) \stackrel{\varnothing}{\varnothing}$ $\mathrm{mm} \mathrm{Hg}$ ).

\section{Nifedipine}

The design of the study with nifedipine resembled $\stackrel{\mathbb{D}}{\AA}$ that of the epoprostenol study. Doses were given $\stackrel{\odot}{\varnothing}$ sublingually at 20 minute intervals. Because nifedipine has a much longer half life than epopros- 


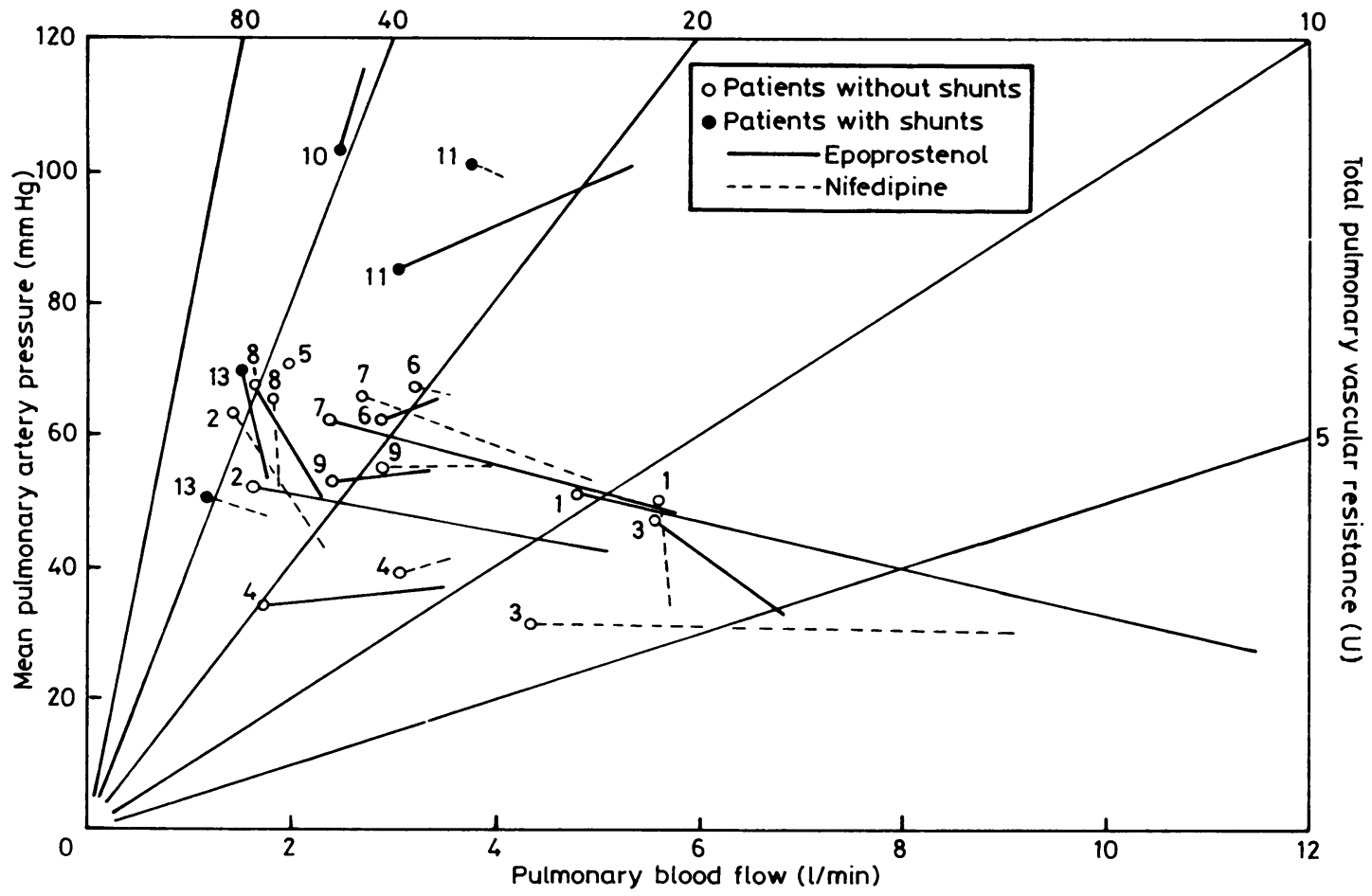

Fig 3 Changes in pulmonary blood flow, pressure, and vascular resistance with epoprostenol or nifedipine in the short term study. Total pulmonary vascular resistance is displayed as lines of equal resistance (5-80 U). An unequivocally favourable response is indicated by a downward sloping line.
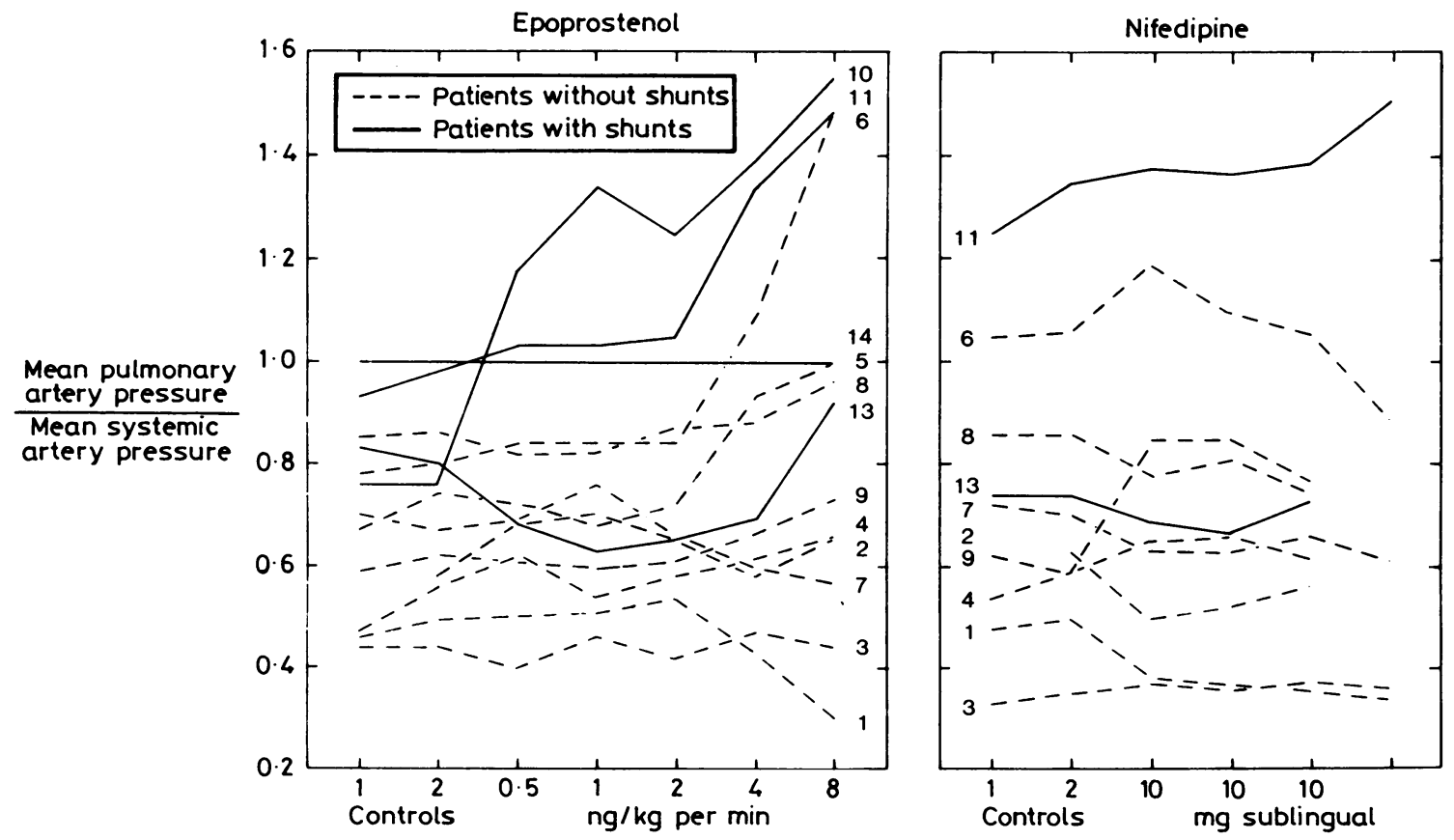

Fig 4 Variation in individual response with drug dose in the short term study. Only patient 1 showed a fall in the ratio of mean pulmonary artery pressure to mean systemic artery pressure; a rise in output with no change in the ratio indicated a favourable response when the cardiac output rose. Patients with interatrial shunts responded badly, except patient 13. Patient 14 , with a ratio of 1 throughout, had a patent ductus arteriosus. 
tenol, the action of the previous dose will have been carried over into the next dose. Thus dose-response curves must be interpreted with more caution.

The observed responses with nifedipine were in the same direction but were less pronounced than those with epoprostenol (figs 1, 3, and 4, table 3).

\section{LONG TERM STUDY}

Patients were subdivided into those with shunts and those without.

\section{Exercise performance off nifedipine}

Heart rate, mean systemic pressure, minute ventilation, and minute oxygen consumption ( $p<0.05$ or less) rose both in patients with shunts and those without. There was a smaller fall in arterial oxygen saturation in those without shunts $(2.8 \%, \mathrm{p}<0.05)$ than in those with shunts $(92.8(2.6)$ to $69 \cdot 1(16.4) \%$, $\mathrm{p}<0.001)$. None had dizziness, syncope, or cardiac arrhythmias during bicycle ergometry. All were stopped by breathlessness. Patient 12 was not exercised because of a history of effort syncope ${ }^{13}$; her symptoms did not improve on nifedipine.

\section{Effect of nifedipine on exercise performance}

Only nifedipine was given in the long term study. The design was open and the exercise performance of 11 patients after three months of treatment was compared with that one week after nifedipine was stopped (table 1). The average maintenance dose was $34 \mathrm{mg}$ daily (range $10 \mathrm{mg}$ twice a day to $20 \mathrm{mg}$ three times a day). The maximum tolerated dose was determined by side effects, particularly headaches and dizziness. None of the patients developed right heart failure. The size of the maintenance dose was not related to the degree of response. Long term treatment with nifedipine had no effect on arterial oxygen saturation. In patients without a shunt, nifedipine increased the heart rate at rest $(p<0.01)$ but reduced the heart rate at peak exercise $(p<0.01)$. There were no such effects in the shunt group. We saw no drug induced changes in systemic blood pressure.

On the basis of the best of the two exercise tests, the mean work performed for all the patients while on nifedipine was 264 (range 24 to 540 ) W and one week after stopping nifedipine it was 243 (range 32 to 420 ). Overall, these differences were not statistically significant but three patients (cases 1,2, and 3) with relatively mild disease showed considerable deterioration in symptoms and decrease in work capacity of 54,48 , and $21 \%$ respectively after stopping nifedipine. The remaining eight showed no improvement in symptoms or work capacity (range +7 to $-24 \%$ ). Patient 4 had shown a similar favourable acute haemodynamic response to the first three patients (fig 3), and at first had a markedly improved exercise tolerance on oral nifedipine. Her deterioration three months later probably reflected progress of her disease. She is the subject of a previous report. ${ }^{14}$ Patients 1 to 4 had a lower pulmonary artery pressure than the others in our series (table 2).

Patients 1 to 4 who responded to epoprostenol in the short term study-that is, they had a greater than $40 \%$ fall in total pulmonary vascular resistance with a dose of $8 \mathrm{ng} / \mathrm{kg}$ per minute-also responded to nifedipine in the long term study; however, patient 4 deteriorated towards the end of the three month period. Patients 7 and 8 who also responded to epoprostenol infusion were in right heart failure at the time of the short term study. Neither improved on oral nifedipine and neither was fit enough to exercise. The control haemodynamic values that were the best discriminators of patients who were likely to respond were a mean pulmonary artery pressure $<50 \mathrm{~mm} \mathrm{Hg}$, a ratio of mean pulmonary to systemic pressure of $<0.6$, and a ratio of total pulmonary to systemic vascular resistance of $<0.7$ (figs 2 to 4 ).

\section{Discussion}

The main object of the study was to investigate the effect of two vasodilators on the pulmonary circulation in patients with severe obliterative pulmonary vascular disease and to identify those patients who were likely to respond favourably to vasodilator treatment. Both drugs reduced the pulmonary and systemic pressure; but the maximum effect of epoprostenol was greater than that of nifedipine. This may have been because the brief duration of action of epoprostenol permitted the infusion to be increased to the maximum tolerated dose, whereas the sublingual doses of nifedipine had a longer half life and the full effect was missed.

The fall in systemic arterial pressure was greater than the fall in pulmonary artery pressure, but when the ratio of pulmonary to systemic pressure was examined over the whole range of doses used there was no systematic change. When the results were taken together, there was no evidence of a selective effect of either drug upon the pulmonary circulation; that is pulmonary vascular resistance did not fall by a greater proportion than did the systemic resistance. Individual responses showed substantial variability and in one patient, who demonstrated the greatest beneficial response to vasodilators, there was a considerable fall in the ratio of pulmonary/systemic pressure during infusions of 4 and $8 \mathrm{ng} / \mathrm{kg}$ per minute of epoprostenol. Two patients without shunts and three with shunts at the atrial level, all of whom had 
severe disease, showed a rise in the ratio (fig 4).

As previous workers have shown, the improvement in cardiac output that is seen with vasodilators can be attributed to pulmonary vasodilatation ${ }^{41516}$-pulmonary artery pressure falls only slightly. ${ }^{17} 18$ Any depressant effect of nifedipine on right ventricular contractile force is thereby obscured. Indeed, right ventricular stroke work was maintained. The more pronounced fall in systemic than pulmonary artery pressure is likely to be a consequence of the absence of fixed disease in the resistance vessels of the systemic bed. Despite the rise in cardiac output there was a fall in systemic blood pressure. This suggests that the normal baroreceptor mediated mechanisms for maintaining systemic pressure were overwhelmed by the action of the vasodilators. The rise in cardiac output was also coupled to an increase in oxygen consumption. This has been seen before after the use of vasodilators in pulmonary hypertension. ${ }^{19}$ The reason is not clear but perhaps oxygen use is greater after redistribution of flow within the tissues when cardiac output is restored. A further possibility is the energy cost of excessive ventilation. With both drugs there was hyperventilation, as judged by a small fall in arterial $\mathrm{PCO}_{2}$ (not significant). It is noteworthy that in five of the patients without shunts resting pretreatment oxygen consumption was less than $90 \%$ of that predicted by the equation of LaFarge and Miettinen ${ }^{20}$ (table 2).

Neither drug caused a significant change in arterial $\mathrm{PO}_{2}$ or oxygen saturation, although one consequence of pulmonary vasodilatation in pulmonary vascular disease is an increase in the ventilation/perfusion mismatch. Any rise in mixed venous oxygen content resulting from an increase in cardiac output ameliorates this adverse effect. ${ }^{21-23}$ The patient with shunts included in the short term study reacted differently from patients without shunts (figs 2 and 3). Vasodilator induced desaturation did not occur, suggesting that the rise in cardiac output, mixed venous oxygen saturation, and ventilation accompanying systemic vasodilatation was sufficient to prevent this despite an increase in right to left intracardiac shunting.

The similarity in the reactions to the two drugs used in this study and the way these altered in a systematic fashion with dose demonstrate the need for adequate dose comparison before it can be concluded that one vasodilator is useful to a patient and another ineffective or dangerous. The maximum dose of nifedipine used in the long term study was limited by side effects that may have been drug specific rather than consequences of the haemodynamic response.

A good response to a vasodilator drug is seen as a rise in cardiac output or a fall in pulmonary artery pressure or preferably both. When there is only a slight response the increase in right ventricular output may result in maintenance of a high pulmonary artery pressure, as was seen in most of our patients. A vasodilator drug with a positive effect on right ventricular contractile force may cause a rise in pulmonary artery pressure despite pulmonary vasodilatation. ${ }^{24}$ Conversely, pulmonary artery pressure can fall without pulmonary vasodilatation, as a result of a fall in output caused by depression of right ventricular function. ${ }^{5}$ That this was not seen with nifedipine suggests that the afterload was reduced by pulmonary vasodilatation in each patient and that this outweighed any depressant effect on the right ventricular myocardium. Nifedipine is known to relax isolated human intrapulmonary arteries..$^{25}$ In another patient, not in this study, administration of nifedipine induced acute right ventricular failure in a man with chronic thromboembolic pulmonary hypertension.

The long term study was open both for ethical reasons and because nifedipine induced symptoms such as headache and flushing in all the patients. The dose of nifedipine was titrated before the patient left hospital. Only four patients showed a favourable response to long term nifedipine and in the fourth patient the improvement was not maintained, probably due to progression of her disease. These four patients had responded favourably to epoprostenol in the short term study. Because the two patients with right heart failure who responded to epoprostenol did not improve with the long term administration of nifedipine, it seems that the long term response could be predicted more accurately from resting haemodynamic variables than from the effect of epoprostenol.

We suggest that short term vasodilator studies should be avoided where possible because they provide little additional information. A favourable response to the long term administration of nifedipine can be expected in patients with primary pulmonary hypertension whose disease is mild or moderate but not in those in whom it is advanced. Only three patients with chronic thromboembolic pulmonary hypertension were tested; none of them responded well in the long term. It is probable that the obstruction to pulmonary blood flow in such cases is much more mechanical rather than vasospastic. None of the patients with the Eisenmenger syndrome responded favourably; they had higher calculated pulmonary vascular resistance than the patients with pulmonary hypertension and no shunts.

We do not know whether long term benefit from nifedipine will remove the need for, or indefinitely 
postpone, heart-lung or lung transplantation in patients with primary pulmonary hypertension who are diagnosed and treated early ${ }^{3}$ but this seems unlikely. ${ }^{26}$ The disease usually becomes worse. ${ }^{27}$ It seems probable that unless the pulmonary artery pressure can be made to fall the disease process will continue to advance ${ }^{28}$ and that amelioration of the patient's symptoms by the rise in output will prove to be temporary. ${ }^{29}$ With our present knowledge, we believe that patients with severe disability, unfavourable haemodynamic features, and particularly those with right ventricular failure, should not be denied transplantation in the hope that they will benefit from vasodilator treatment. There may, however, be a role for vasodilator treatment in patients awaiting heart-lung transplantation. ${ }^{29}$

\section{Conclusions}

The short term actions of epoprostenol and nifedipine in patients with severe pulmonary hypertension were very similar. Criteria for the prediction of a favourable clinical response to oral nifedipine were evaluated and resting haemodynamic variables were found to be as useful as the responses to short term treatment in the patients studied. Failure to titrate the dose has in part been responsible for a false impression that one vasodilator agent is effective when another is not ${ }^{30}$. Epoprostenol seems to have no advantage over nifedipine that would justify attempts to use this drug for long term treatment with all the attendant difficulties, hazards, and costs of prolonged intravenous treatment.

We thank David Wright for assistance with statistical analysis and Keith Minty for technical help. We thank Wellcome Research Laboratories for the supply of epoprostenol.

\section{References}

1 Lupi-Herrera E, Sandoval J, Seoane M, Bialostozky D. The role of hydralazine therapy for pulmonary arterial hypertension of unknown cause. Circulation 1982;65:645-50.

2 McGoon MD, Seward JB, Vlietstra RE, Choo MH, Moyer TP, Reeder GS. Haemodynamic response to intravenous hydralazine in patients with pulmonary hypertension. Br Heart J 1983;50:579-85.

3 Rich S, Brundage $\mathrm{BH}$, Levy PS. The effect of vasodilator therapy on the clinical outcome of patients with primary pulmonary hypertension. Circulation 1985;71:1191-6.

4 Brent BN, Berger HJ, Matthay RA, Mahler D, Pytlik L, Zaret BL. Contrasting acute effects of vasodilators (nitroglycerin, nitroprusside, and hydralazine) on right ventricular performance in patients with chronic obstructive pulmonary disease and pulmonary hyptertension: a combined radionuclide-hemodynamic study. Am J Cardiol 1983;51:1682-9.

5 Packer M, Medina N, Yushak M. Adverse hemodynamic and clinical effects of calcium channel blockade in pulmonary hypertension secondary to obliterative pulmonary vascular disease. J Am Coll Cardiol 1984;4:890-901.

6 Groves BM, Rubin LJ, Frosolono MF, Cato AE, Reeves JT. A comparison of the acute hemodynamic effects of prostacyclin and hydralazine in primary pulmonary hypertension. Am Heart $J$ 1985;110: $1200-4$.

7 Sackner MA, Akgun N, Kimbel P, Lewis DH. The pathophysiology of scleroderma involving the heart and respiratory system. Ann Intern Med 1964;60: 611-30.

8 Lisbona R, Kreisman H, Novales-Diaz J, Derbekyan V. Perfusion lung scanning: differentiation of primary from thromboembolic pulmonary hypertension. $\mathrm{Am}$ J Roentgenol 1985;144:27-30.

9 Zielinski J. Intrathoracic pressure variations and pulmonary artery pressure in patients with chronic obstructive lung disease. Bull Eur Physiopathol Respir 1979;15:397-405.

10 Smits P, Thien T, van't Lear A. Circulatory effects of coffee in relation to the pharmacokinetics of caffeine. Am J Cardiol 1985;56:958-63.

11 Jones NL, Campbell EJM. Clinical exercise testing. 2nd ed. Philadelphia: W B Saunders, 1982.

12 Stradling JR. The accuracy of the Hewlett-Packard 47201A ear oximeter below 50\% saturation. Bull Eur Physiopathol Respir 1982;18:791-4.

13 Howarth S, Lowe JB. The mechanism of effort syncope in primary pulmonary hypertension and cyanotic congenital heart disease. Br Heart J 1953;15:47-54.

14 Rozkovec A, Bernstein R, Asherson RA, Oakley CM. Vascular reactivity and pulmonary hypertension in systemic sclerosis. Arthritis Rheum 1983;26:1237-40.

15 Lupi-Herrera E, Sandoval J, Seoane M, Bialostozky D. The role of hydralazine therapy for pulmonary arterial hypertension of unknown cause. Circulation 1982;65:645-50.

16 Rich S, Martinez J, Lam W, Levy PS, Rosen KM. Reassessment of the effects of vasodilator drugs in primary pulmonary hyptertension: guidelines for determining a pulmonary vasodilator response. $\mathrm{Am}$ Heart J 1983;105:119-27.

17 Rubin LJ, Groves MB, Reeves JT, Frosolono M, Handel F, Cato AE. Prostacylin-induced acute pulmonary vasodilation in primary pulmonary hypertension. Circulation 1982;66:334-8.

18 Rubin LJ, Nicod P, Hillis LD, Firth BG. Treatment of primary pulmonary hypertension with nifedipine. A hemodynamic and scintigraphic evaluation. Ann :Intern Med 1983;99:433-8.

19 Rubin LJ, Peter RH. Oral hydralazine therapy for primary pulmonary hyptertension. $N$ Engl J Med 1980;302:69-73.

20 LaFarge CG, Miettinen OS. The estimation of oxygen consumption. Cardiovasc Res 1970;4:23-30. 
21 Dantzker DR, Bower JS. Pulmonary vascular tone improves VA/Q matching in obliterative pulmonary hypertension. J Appl Physiol 1981;51:607-13.

22 Simmonneau G, Esourrou P, Duroux P, Lockhart A. Inhibition of hypoxic pulmonary vasoconstriction by nifedipine. $N$ Engl J Med 1981;304:1582-5.

23 Kennedy TP, Michael JR, Huang C-K, et al. Nifedipine inhibits hypoxic pulmonary vasoconstriction during rest and exercise in patients with chronic obstructive pulmonary disease. A controlled doubleblind study. Am Rev Respir Dis 1984;129:544-51.

24 Fried R, Reid LM. The effect of isoproterenol on the development and recovery of hypoxic pulmonary hypertension. A structural and hemodynamic study. Am J Pathol 1985;121:102-11.

25 Mikkelsen EO, Sakr AMR, Jespersen LT. Effects of nifedipine on contractile responses to potassium, histamine, and 5-hydroxytryptamine in isolated human pulmonary vessels. J Cardiovasc Pharmacol 1983;5:317-20.
26 Reeves JT, Groves BM, Turkevich D. The case for treatment of selected patients with primary pulmonary hypertension. Am Rev Respir Dis 1986;134:342-6.

27 Rozkovec A, Montanes P, Oakley CM. Factors that influence the outcome of primary pulmonary hypertension. Br Heart $J$ 1986;55:449-58.

28 Wagenvoort CA, Nauta J, van der Schaar PJ, Weeda HWH, Wagenvoort N. Effect of flow and pressure on pulmonary vessels. A semiquantitative study based on lung biopsies. Circulation 1967; 35:1028-37.

29 Jones DK, Higenbottam TW, Wallwork J. Treatment of primary pulmonary hypertension with intravenous epoprostenol (prostacyclin). Br Heart J 1987;57: $270-8$.

30 Rich S, Brundage BH. High-dose calcium channelblocking therapy for primary pulmonary hypertension: evidence for long-term reduction in pulmonary arterial pressure and regression of right ventricular hypertrophy. Circulation 1987;76:135-41. 